\title{
Removal of Chromium (VI) From Aqueous Solution using Chemically-Modified Sweet Lime (Citrus Limetta) Peels as Adsorbent
}

\author{
Devi Lal Adhikari' ${ }^{1}$, Ram Lochan Aryal' ${ }^{\text {, Sitaram Bhattarai }}{ }^{1}$ Surendra Kumar Gautam ${ }^{1}$ and \\ Bhoj Raj Poudel ${ }^{\text {* }}$ \\ ${ }^{I}$ Department of Chemistry, Tri-Chandra Multiple Campus, TribhuvanUniversity,Nepal \\ ${ }^{2}$ Department of Chemistry,Amrit Campus, TribhuvanUniversity,,Nepal \\ E-mail : bhojrajpoudel@yahoo.com
}

\begin{abstract}
Chromium is toxic metal which is introduced in to the ecosystem as a result of various industrial operations like leather tanning, textile, electroplating, metal finishing, paint industry, chromate preparation,etc. Since the Cr(VI) is priority toxic, mutagenic, carcinogenic, non-biodegradable and can accumulate in the tissues, the presence and release of this element through the effluents is associated with dangerous effect on life cycle.Thus, in this research work adsorption of Cr(VI) ions on raw Citrus limetta peels (RCLP) and chemically modified Citrus limetta peels (CMCLP) has been studied by using batch adsorption technique.To evaluate the different batch parameters like $\mathrm{pH}$, initial concentration, adsorbent dose and contact time Citrus limetta peels were investigated. Results show that all parameters effect on the adsorption removal of $\mathrm{Cr}(V I)$ ion. The maximum removal of $\mathrm{Cr}(V I)$ was found at $\mathrm{pH} 1$, initial concentration $20 \mathrm{mg}$, equilibrium time 120 minutes, adsorbent dose $150 \mathrm{mg}$. Pseudo second order kinetic model is followed by kinetic data.Langmuir and Freundlich isotherm model were followed by dsorption data but best fitting model is Freundlich isotherm. The maximum Cr (VI) removal were found to be $186.08 \mathrm{mg} / \mathrm{g}$ and $228.1 \mathrm{mg} / \mathrm{g}$ for raw Citrus limetta peels and chemically modified Citrus limetta peels respectively. Sample characterization before and after adsorption was analyzed by FT-IR, XRD and Boehm titration. From the experimental result it can be concluded that the raw Citrus limetta peels and chemically modified Citrus limetta peels can be employed as low-cost alternative commercial adsorbent to removal of $\mathrm{Cr}(V I)$ from waste water.
\end{abstract}

Key words: Cr(VI), adsorption isotherm, batch experiment, Citrus limetta

\section{Introduction}

Pollution is the process of mixing of unwanted factors in natural resource. There are different types of pollution. Most of them water pollution is a one of the digest problem of environment. Water is the most vital elements among the natural resources, and crucial for the survival of all living organisms but increasing urbanization and industrialization have negative implications for water bodies. Various types of ill effects of pollutions are due to each types of pollutants on human, plants, animals and ecology. ${ }^{1,2}$ Heavy metal pollution is one of the main problem because they are non-biodegradable. Naturally heavy metals are release from rock-forming, ore, minerals, soil, sediments and mining process. $\mathrm{Cr}(\mathrm{VI})$ also

* Corresponding author 
releases from different types of industries like metallurgy, battery manufacturing, mine, drainage, chemical manufacturing, leather tanning and electroplating industries etc, ${ }^{3,4}$

Heavy metals (sp. wt. $>5.0 \mathrm{~g} / \mathrm{cm}^{3}$ ), which are heavier than water, are considered as toxic pollutants due to their toxicity occurs even in low concentrations of about $1.0-10 \mathrm{mg} / \mathrm{L}$. For human, $\mathrm{Cr}(\mathrm{VI})$ is known astoxic, carcinogenic and mutagenic by the inhalation of $\mathrm{Cr}(\mathrm{VI})$ compounds. The international agency for research on cancer (IARC) has classified $\mathrm{Cr}(\mathrm{VI})$ compounds in group I as carcinogenic to human . $5,6,7$

In most of the countries, have their own strict legislations to control water pollution. Various regulatory system has set the maximum prescribed limits for the discharge of toxic heavy metals in aquatic system. The prescribed limits of heavy metals $(\mathrm{mg} / \mathrm{L})$ by WHO are $5-15(\mathrm{Zn}), 0.05-05(\mathrm{Cu})$, 0.1(Cd), 0.1(Pb), 0.1-1.0(Fe),0.05-0.5(Mn) and 0.05-0.5(Cr) ${ }^{8,9,10}$.

The chromium exists in different oxidation state, $\mathrm{Cr}(\mathrm{III})$ and $\mathrm{Cr}(\mathrm{VI})$ are most common due to their stability in water. In contaminant environment, dominant toxicity of $\mathrm{Cr}(\mathrm{VI})$ is due to the presence in the form of acid chromate $\left(\mathrm{HCrO}_{4}^{-}\right)$, chromate $\left(\mathrm{CrO}_{4}^{2-}\right)$ and dichromate $\left(\mathrm{Cr}_{2} \mathrm{O}_{7}^{2-}\right)$ ions than the other valence states.$^{11,12}$

Chromium generally used in different industry as planting, alloying, tanning of animal hides, inhibition of water corrosion, textile, dyes, pigments, ceramic glazes, refractory bricks and pressure treated lumber. Due to these wide anthropogenic uses of chromium the environmental contamination has been increasing. Chromium is poisons, carcinogenic and different diseases causing element. It causes cancer, anuria, nephritis, gastro intestinal ulceration, perforation in partition of nose, affects the central nervous system, causes respiratory trouble and lung tumor by inhaled, so study on removal of heavy metal pollutions are increasing challenges. ${ }^{2,4,13}$

In order to overcome such pollution from industrial waste water various type of physical, chemical and biological methods are available, some of them are chemical precipitation, ion exchange, reduction, electrochemical precipitation, solvent extraction, membrane separation, evaporation, foam separation coagulation, flotation, crystallization and ultrafiltration, one of them bioadsorption method is most important.$^{14,15}$

Bioadsorption has been emerged as an attractive process due to its ease to handle and efficiency for removing toxic substances. ${ }^{16}$ Bioadsorption is a most convenient treatment method because it includes low cost high efficiency of metal removal, minimization of chemical biological sludge, no additional substituents required, regeneration of bioadsorbent, and Eco friend. ${ }^{17}$

Citrus limetta fruits are very famous in all season for juice, commonly known as sweet limes. ${ }^{18}$ Citrus limetta fruits choose as the bioadsorbents for removal of hexavalent chromium from water, which is common waste, highly effective possibility of metal recover; no need for any additional nutrient require for metal recovery from waste water ${ }^{6}$. The composition of Citrus limetta peel contains soluble sugar a pectin as main component. The Citrus limetta peel is a fact constituted by soluble sugar is $16.9 \%$, weight of starch is $3.75 \%$, weight of fiber(cellulose) is $9.221 \%$,weight. of hemicellulose $10.5 \%$,weight of lignin is $0.84 \%$, weight of pectin is $42.5 \%$, ashes $3.5 \%$ fats are $19.5 \%$ weight of protein $6.5 \%$ by weight. ${ }^{19,20}$ 
The bioadsorption capacity of bio adsorbent can determine by varying, concentration of $\mathrm{Cr}(\mathrm{VI})$ solution, $\mathrm{pH}$ of solution, adsorbent dose, effect of contact time and temperature keeping other constant. The amount of $\mathrm{Cr}(\mathrm{VI})$ adsorbed per unit mass of adsorbent is measured by the relation ${ }^{6,19,21}$

$$
\begin{aligned}
& \mathrm{q}_{\mathrm{e}}=\frac{\mathrm{C}_{\mathrm{i}}-\mathrm{C}_{\mathrm{e}}}{\mathrm{W}} \times \mathrm{V}(m g / g) \ldots \ldots \ldots(1) \\
& \text { where, } \\
& \mathrm{W}=\text { weight } \text { of adsorbent }(g) \\
& \mathrm{C}_{\mathrm{i}}=\text { initial concentration of adsorbate }(\mathrm{mg} / L) \\
& \mathrm{C}_{\mathrm{e}}=\text { equilibrium concentration of adsorbate }(\mathrm{mg} / \mathrm{L}) \\
& \mathrm{V}=\text { volume of adsorbate (L) } \\
& \text { The percent removal of } \mathrm{Cr}(\mathrm{VI}) \text { can be calculated as follows }{ }^{16,21,22} \\
& \text { Percentage removal }(\mathrm{R} \%)=\frac{\mathrm{C}_{\mathrm{i}}-\mathrm{C}_{\mathrm{e}}}{\mathrm{C}_{\mathrm{i}}} \times 100 \% \\
& \text { where, } \\
& \mathrm{C}_{\mathrm{i}}=\text { initial concentration of adsorbate }(\mathrm{mg} / \mathrm{L}) \\
& \mathrm{C}_{\mathrm{e}}=\text { equilibrium concentration of adsorbate }(\mathrm{mg} / \mathrm{L})
\end{aligned}
$$

\section{Experimental Methods}

\section{Chemical and Instruments}

All the chemical reagents were of LR/AR grade and used without any further purification. Some used chemicals were hydrochloric acid $(\mathrm{HCl})$, sulphuric acid $\left(\mathrm{H}_{2} \mathrm{SO}_{4}\right)$, Diphenyl carbazide [Co (NH.NHC 6 $\left.\mathrm{H}_{5}\right)_{2}$ ], buffer tablet of $\mathrm{pH} 4$ and $\mathrm{pH} 9.2$ and potassium dichromate solution $\left(\mathrm{K}_{2} \mathrm{Cr}_{2} \mathrm{O}_{7}\right)$ and instruments used in lab were weighing balance: D-72336, Balingen Germany, hot air oven, pH meter: 101, Sieve: 150 $\mu \mathrm{m}$, Spectrophotometer: ELICO/SL177,shaker-FLASK SHAKER SF1-UK,volumetric flask and Whatman filter paper.

\section{Preparation of Bioadsorbents}

\section{Raw Citrus limetta Peels Powder}

Citrus limetta peels were collected from fruit juice shop near the Banesawor Kathmandu. The collected peels were washed with distilled water and then kept to dry for two-week in sunlight. After complete drying, it was grinded and screened. The grinded peels powder was passed through sieves of size $150 \mu \mathrm{m}$.

\section{Chemically Modified Citrus limetta Peels Powder}

The grinded Citrus limettapeels was treated with concentrated sulphuric acid solution to improve the efficiency of metal uptake for this $50 \mathrm{~g}$ of raw peels powder was treated with concentrated sulphuric acid solution for 48 hours in shaker with continuous shaking at $120 \mathrm{rmp}$. After repeated decantation and filtration, the chemically modified biomass was washed with distilled water until the neutral $\mathrm{pH}$ value of filtrate. Then the modified biomass was dried on oven at $80{ }^{\circ} \mathrm{C}$ to get constant mass and which was stored in air tight bottle. 


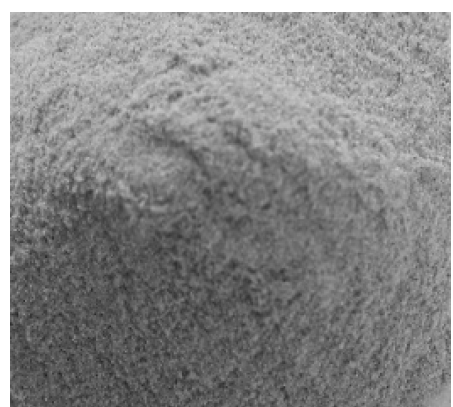

Figure 1: (i) RCLP

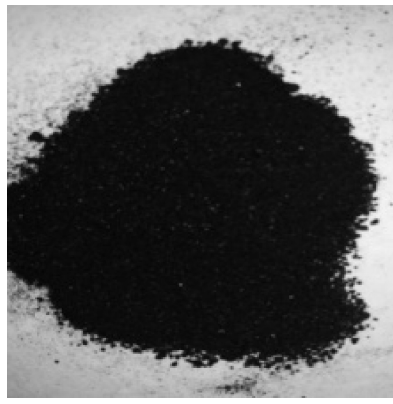

(ii) CMCLP
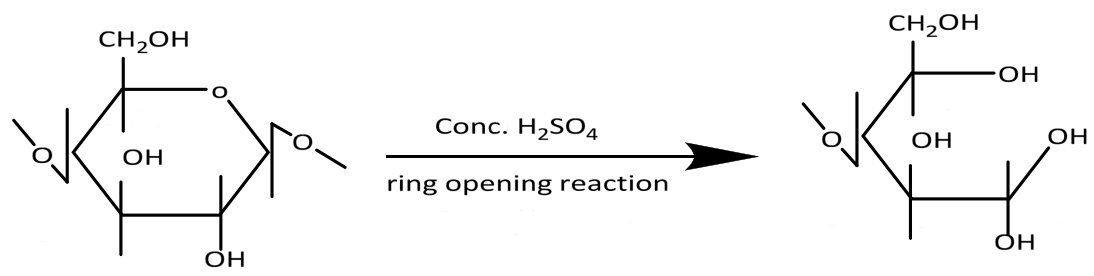

Figure 2: Plausible reaction scheme for charring with sulphuric acid ${ }^{13}$

\section{Preparation of Stock Solution}

Stock solution $(1000 \mathrm{ppm})$ of potassium dichromate $\left(\mathrm{K}_{2} \mathrm{Cr}_{2} \mathrm{O}_{7}\right)$ was prepared by dissolving 2.45 gram $\mathrm{K}_{2} \mathrm{Cr}_{2} \mathrm{O}_{7}$ was taken in $1000 \mathrm{~mL}$ volumetric flask and dissolve in $0.1 \mathrm{~N}$ nitric acid and make up to mark.

\section{Results and Discussion}

\section{Characterization of Bioadsorbent}

\section{FT-IR Analysis}

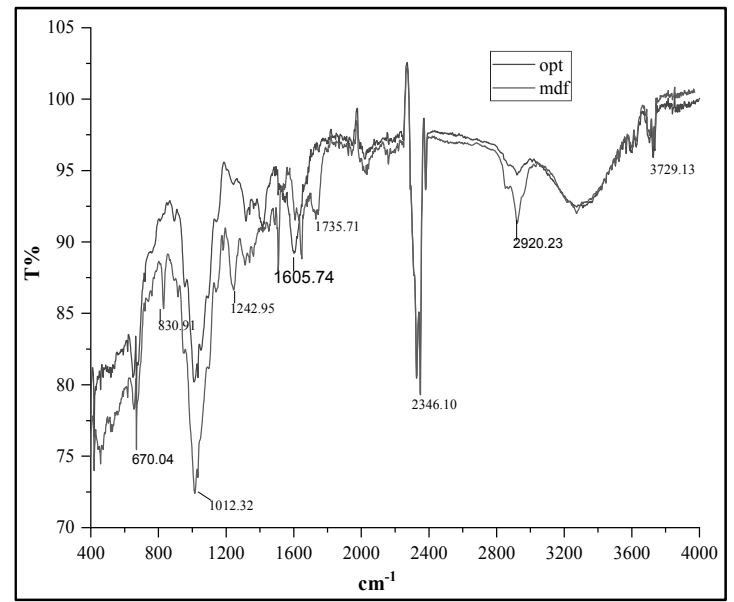

Figure 3: FT-IR spectrum of CMCLP and MACLP 
FT-IR analysis for modified sample is shown in Figure 3, from the figure and from data analysis, it is clear that lots of change have been done, like band at

$1735 \mathrm{~cm}^{-1}$ have been shifted to $1600.92 \mathrm{~cm}^{-1}$, which is due to the conversation of methyl ester and non- ionic carboxyl group into ionic form by reaction with concentrated sulphuric acid. Another change was new peak appeared at $1415.75 \mathrm{~cm}^{-1}$ and $1315.45 \mathrm{~cm}^{-1}$ which indicates that there is presence of alcohol, carboxylic acid, ester and ether etc,., ${ }^{6,10,12,19}$

XRD Analysis

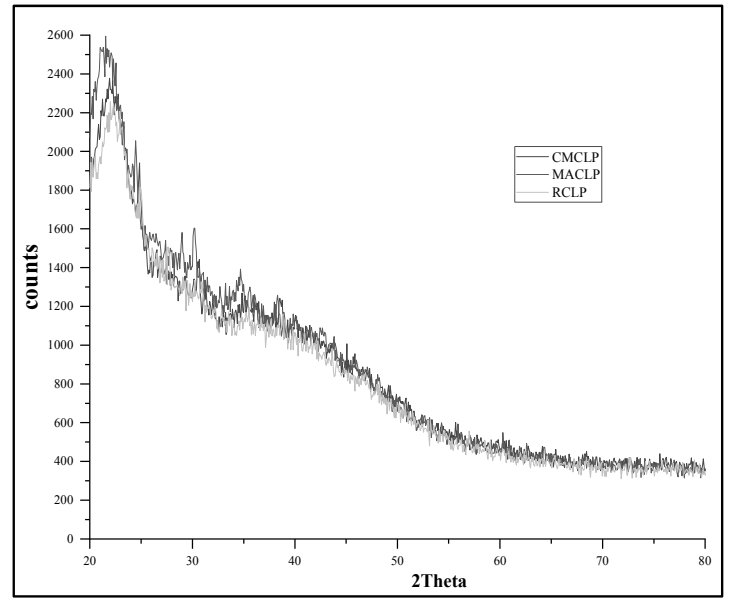

Figure 4: XRD analysis data for RCLP, CMCLP and MACLP

XRD graph of bioadsorbent are given in Figure 4, from the graph, it can be said that morphology of bioadsorbent is amorphous nature.

\section{Boehm Titration}

Boehm technique was applied to characterized the surface chemical properties of RCLP and CMCLP. There are various assumptions to calculate the surface acidic and basic group. In this technique, it was assumed that acidic group are generally could only be neutralized by $\mathrm{NaOH}$ and all the basic group would be neutralized by $\mathrm{HCl}$. Table 1 shows the summary of the properties of the surface functional group through the Boehm titration. The significant increase in acidic group in comparison to the basic group suggest that the majority of the functional group on the adsorbent surface are acidic. The more acidic groups indicating present of more oxygenated functional groups, give rise to higher adsorption of heavy metals. ${ }^{12,22,23}$

Table 1: Boehm's titration data for RCLP and CMCLP

\begin{tabular}{|l|c|c|}
\hline \multirow{2}{*}{ Bio sorbent } & \multicolumn{2}{|c|}{ Boehm's titration method } \\
\cline { 2 - 3 } & Acidic $(\boldsymbol{m m o l} / \boldsymbol{g})$ & Basic $(\boldsymbol{m m o l} / \boldsymbol{g})$ \\
\hline RCLP & 0.041 & 0.034 \\
\hline CMCLP & 0.058 & 0.025 \\
\hline
\end{tabular}

$-86-$ 


\section{Batch Adsorption Experiments}

Preparation of Calibration Curve

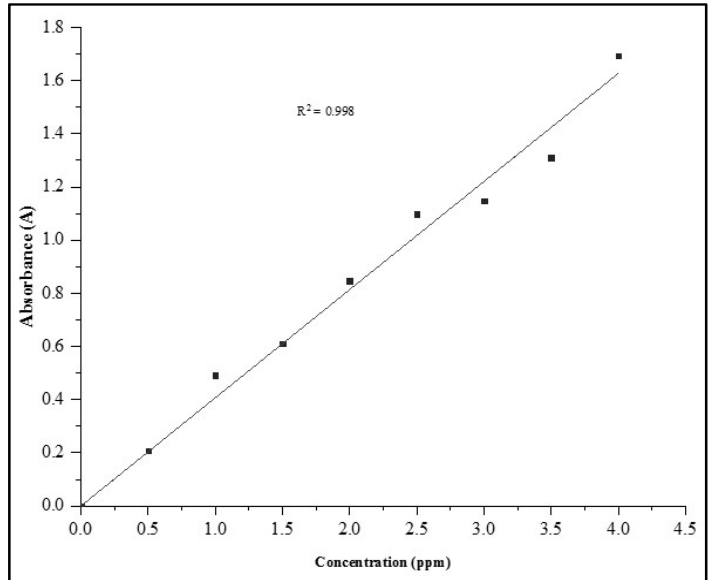

Figure 5: Absorbance versus concentration of Cr (VI) in ppm

Diphenyl-carbazide complex method was used to determine $\lambda_{\max }$ Here the maximum absorption of $\mathrm{Cr}$ (VI) - DPCI complex was found at $540 \mathrm{~nm} 12$ The calibration curve of $\mathrm{Cr}$ (VI) was determine at $\lambda_{\max }, 540$ nmby varying the concentration of $\mathrm{Cr}(\mathrm{VI})$-DPCI complex solution as shown in Figure 5, which helps to determine directly measurable range by method of standard addition and dilution.

\section{Effect of pH}

Figure 6 shows the removal of $\mathrm{Cr}(\mathrm{VI})$ at various $\mathrm{pH}$ range, applying others parameters constant. Maximum adsorption of $\mathrm{Cr}(\mathrm{VI})$ ions observed at $\mathrm{pH} 1$ for RCLP and CMCLP. At lower $\mathrm{pH}$, the surface of adsorbent is highly protonated, which allows the electrostatic interaction with predominant anionic form $\left(\mathrm{HCrO}_{4}^{-}, \mathrm{CrO}_{4}^{2-}\right.$ and $\left.\mathrm{Cr}_{2} \mathrm{O}_{7}^{2-}\right)$ of $\mathrm{Cr}(\mathrm{VI})$. In acidic range, these anions have greater affinity towar ds hydrogen ions present on the surface of bioadsorbent. As the $\mathrm{pH}$ increases $\mathrm{OH}^{-}$also increase on surface and solution, so both $\mathrm{OH}^{-}$and $\mathrm{HCrO}_{4}^{-}$ions compete to each other and removal of $\mathrm{Cr}(\mathrm{VI})$ is decreases. $^{21}$

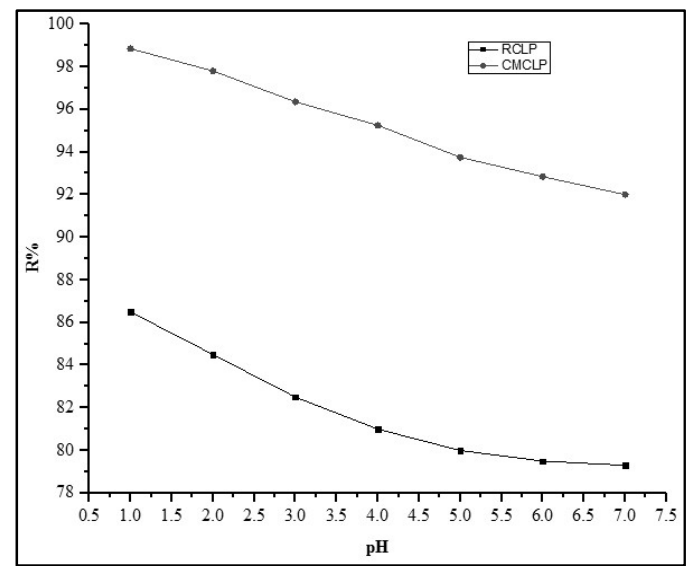

Figure 6: Effect on pH on the adsorption of Cr(VI) onto RCLP and CMCLP 


\section{Effect of Concentration}

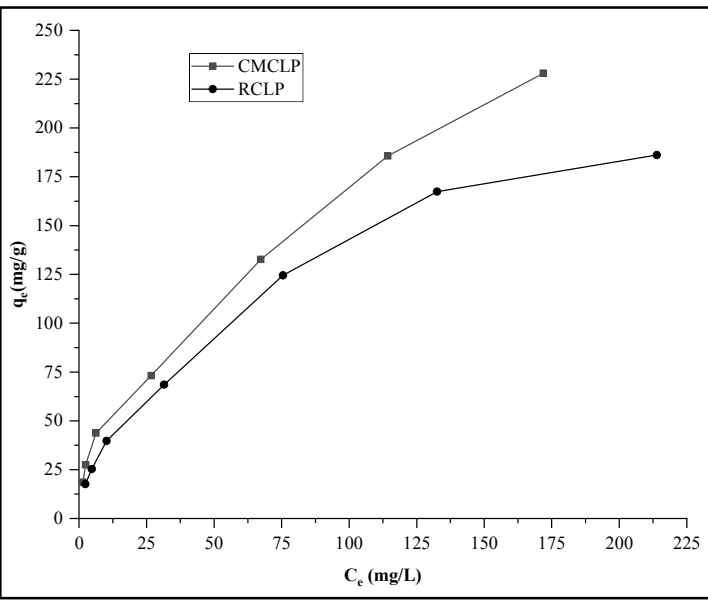

Figure 7: Effect of initial concentration on the adsorption of Cr(VI) onto RCLP and CMCLP

The amount of chromium adsorbed $\left(\mathrm{q}_{\mathrm{e}}\right)$ increase with increasing initial concentration of test solution, whereas removal percent $(\mathrm{R} \%)$ decrease with increasing initial metal ion concentration. This type of result is mainly due to the interaction of ions with binding sites and significant driving force ions. ${ }^{15,19,21}$

\section{Effect of Adsorbent Dose}

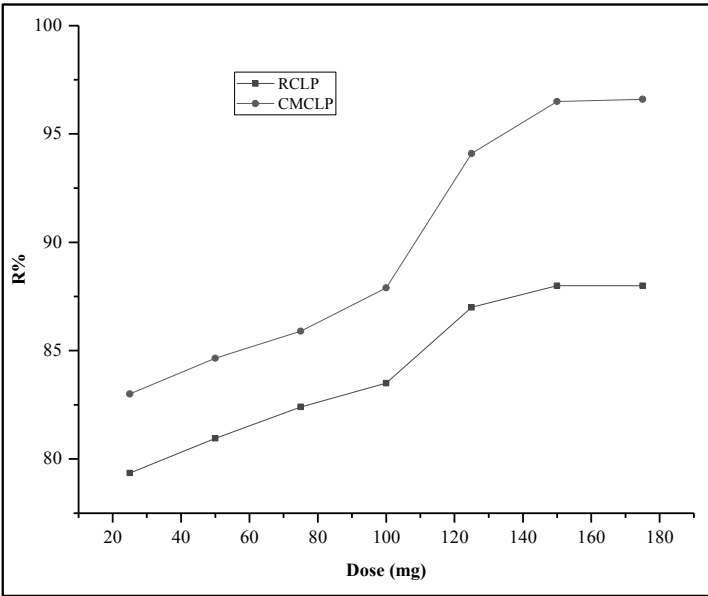

Figure 8: Effect of adsorbent dose on adsorption of Cr(VI) onto RCLP and CMCLP

The result from indicates that, the percent removal of $\mathrm{Cr}(\mathrm{VI})$ increasing with increase in the adsorbent dose but unit adsorption decreases with increase in dose, it is mainly due to the aggregation and number of active sites available for bioadsorption. The adsorption rate of CMCLP is higher in comparison of RCLP as shown in fig 8. It is mainly due to the increase of active sites, better exchange rate and increasement of new functionality by chemical modification. ${ }^{20,24}$ 


\section{Effect of Contact time}

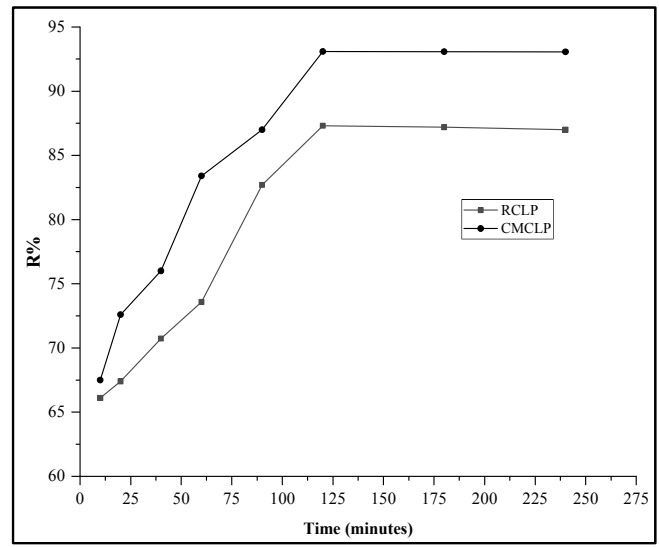

Figure 9: Effect of contact time on the adsorption of Cr(VI) onto RCLP and CMCLP

Figure 9 shows that percentage removal is increasing up to the 120 minutes then remaining constant, is due to available of large surface area of bioadsorbent and high concentration gradient at initial time, after that active sites of adsorbent get exhausted .9,19

\section{Adsorption Isotherm}

Adsorption isotherm is a process of metal uptake per unit mass of adsorbent to equilibrium adsorbate concentration in the bulk of fluid phase based on homogeneity or heterogeneity nature of adsorbent, interaction between the adsorbate species and adsorbent and types of coverage. Usually adsorption data can be analyzed by the adsorption isotherm model. Such as Langmuir and Freundlich isotherms. These isotherms relate metal uptake per unit mass of adsorbent $\left(\mathrm{q}_{\mathrm{e}}\right)$ to the equilibrium adsorbate concentration in the bulk fluid phase (Ce). ${ }^{4,25}$

\section{Langmuir Isotherm}

Langmuir isotherm is based on the assumption that "maximum adsorption occurs when a saturated monolayer of solute molecules is present on the adsorbent surface". The energy of adsorbent is constant and there is no migration of adsorbate molecules in the surface plane. ${ }^{4,18,26,27}$

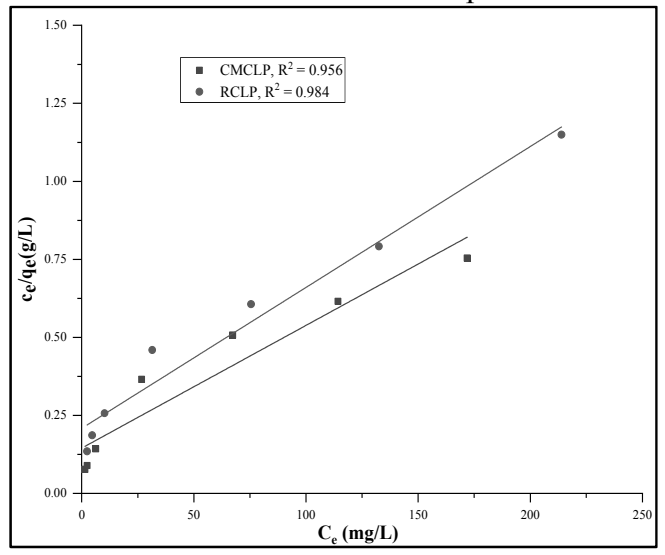

Figure 10: Langmuir adsorption isotherm for the adsorption of Cr(VI) onto RCLP and CMLCP 
The $\mathrm{R}_{\mathrm{L}}$ values from Langmuir isotherm model found to be 0.68 and 0.67 for RCLP and CMCLP respectively. Which belong to range $0<\mathrm{R}_{\mathrm{L}}<1$, which is indicated that the process is favorable and adsorption data well fit in Langmuir adsorption isotherm.

\section{Freundlich Adsorption Isotherm}

The Freundlich isotherm helps to determine the equilibrium relationship between solid and liquid phase capacity based on multilayer adsorption properties consisting heterogeneous surface of adsorbent . 28,29

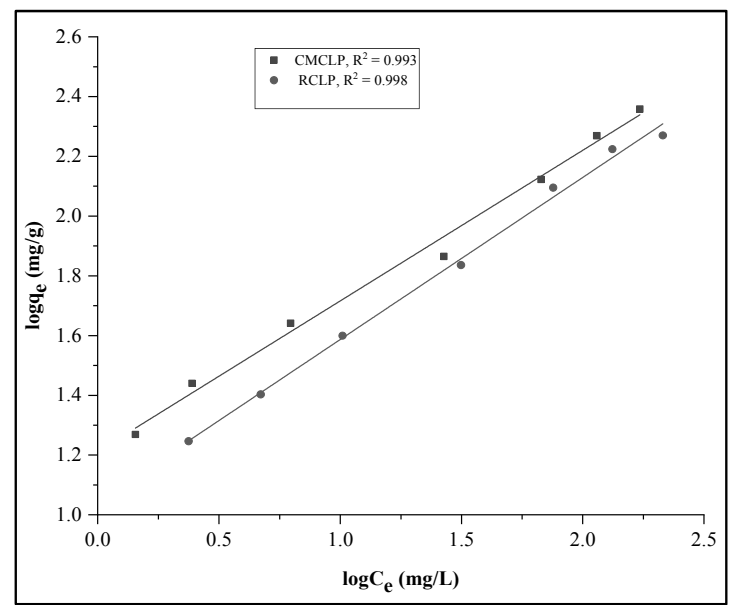

Figure 11: Freundlich adsorption isotherm for the adsorption of Cr(VI) onto RCLP and CMLCP

Freundlich isotherm the values of $1 / n$ equals to 0.54 and 0.50 for RCLP and CMCLP respectively and lies between 0 and 1, which indicated that Freundlich isotherm also followed by the resulting data. The comparison between correlation coefficient values of Langmuir and Freundlich adsorption isotherm indicate that Freundlich adsorption isotherm is better than Langmuir adsorption isotherm. ${ }^{12,14}$

Table 2: Langmuir and Freundlich parameters for the adsorption of $\mathrm{Cr}(\mathrm{VI})$ onto RCLP and CMCLP

\begin{tabular}{|c|c|c|c|c|c|c|c|}
\hline \multirow[t]{2}{*}{ Adsorbent } & \multirow{2}{*}{$\begin{array}{c}\text { Exp. } \\
\boldsymbol{q}_{\boldsymbol{m}} \\
(\boldsymbol{m g} / \boldsymbol{g})\end{array}$} & \multicolumn{3}{|c|}{ Langmuir isotherm } & \multicolumn{3}{|c|}{ Freundlich isotherm } \\
\hline & & $\begin{array}{c}\boldsymbol{q}_{\boldsymbol{m}} \\
(\boldsymbol{m} \boldsymbol{g} / \boldsymbol{g})\end{array}$ & $\begin{array}{c}b \\
(\boldsymbol{m} g / L)\end{array}$ & $R^{2}$ & $\begin{array}{c}\boldsymbol{K} \\
(\boldsymbol{m} \boldsymbol{g} / \boldsymbol{g})\end{array}$ & $1 / n$ & $\boldsymbol{R}^{2}$ \\
\hline RCLP & 186.0 & 221.2 & 0.025 & 0.984 & 10.9 & 0.543 & 0.998 \\
\hline CMCLP & 228.1 & 254.4 & 0.027 & 0.956 & 16.29 & 0.502 & 0.993 \\
\hline
\end{tabular}

\section{Batch Kinetic Studies}

The adsorption kinetics explain the reaction process along time to reach the equilibrium. Which is depends upon the different chemical and physical properties of bio sorbent materials. Which is also influence the sorption mechanism in order to identify the mechanism of sorption. There is some useful model to use at different experimental condition for the sorption process . $9,19,24,28$ 


\section{Pseudo First Order Model}

This is the first equation for the sorption process based on solid capacity. This model can be expressed as

$$
\frac{d q_{t}}{d t}=K_{1}\left(q_{e}-q_{t}\right)
$$

Equation (9) can be integrated for the boundary condition then

$$
\begin{gathered}
\mathrm{t}=0, \quad \mathrm{q}_{\mathrm{t}}=0, \mathrm{t}=\mathrm{t}, \mathrm{q}_{\mathrm{t}}=\mathrm{q}_{\mathrm{t}} \\
\log \left(\mathrm{q}_{\mathrm{e}}-\mathrm{q}_{\mathrm{t}}\right)=\log \mathrm{q}_{\mathrm{e}}-\frac{\mathrm{K}_{1}}{2.303} \mathrm{t} \ldots \ldots
\end{gathered}
$$

Where, $\mathrm{q}_{\mathrm{t}}$ is the amount of solute on the surface of adsorbent at time ' $\mathrm{t}$ ' and qe is the amount of adsorbent at equilibrium and $\mathrm{K} 1$ is the equilibrium rate constant of pseudo first order.qe and $\mathrm{K} 1$ are calculated by using the intercept and slope on $\log \left(\mathrm{q}_{\mathrm{e}}-\mathrm{q}_{\mathrm{t}}\right)$ against time (minutes) plots.

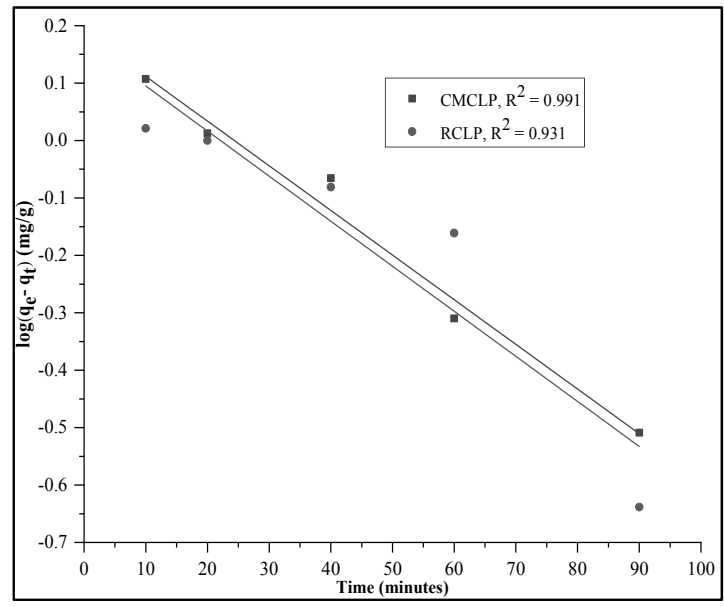

Figure 12: Pseudo first order kinetic model for adsorption od Cr(VI) onto RCLP and CMCLP

\section{Pseudo Second Order Model}

The pseudo second order model can be expressed as

$$
\frac{\mathrm{dq}}{\mathrm{dt}}=\mathrm{K}_{2}\left(\mathrm{q}_{\mathrm{e}}-\mathrm{q}_{\mathrm{t}}\right)^{2}
$$

By integrating equation (11), for boundary condition rearranging it to obtain the linearized formwe get, $\mathrm{t}=0, \mathrm{q}_{\mathrm{t}}=0, \mathrm{t}=\mathrm{t}, \mathrm{q}_{\mathrm{t}}=\mathrm{q}_{\mathrm{t}}$

$$
\begin{gathered}
\frac{t}{q_{t}}=\frac{1}{K_{2} q_{e}^{2}}+\frac{1}{q_{e}} t \ldots . \\
V_{o}=K_{2} q_{e}^{2} \ldots \ldots \ldots \ldots
\end{gathered}
$$

Then, equation (12) will be $\frac{\mathrm{t}}{\mathrm{q}_{\mathrm{t}}}=\frac{1}{\mathrm{v}_{\mathrm{o}}}+\frac{1}{\mathrm{q}_{\mathrm{e}}} \mathrm{t} \ldots \ldots$ (14)

Where, $\mathrm{K}_{2}$ is the equilibrium rate constant and $\mathrm{V} 0$ is the initial sorption rate. The equilibrium constant can be determined by plotting $t / q_{t}$ versus ' $t$ '. $3,4,9,21$ 


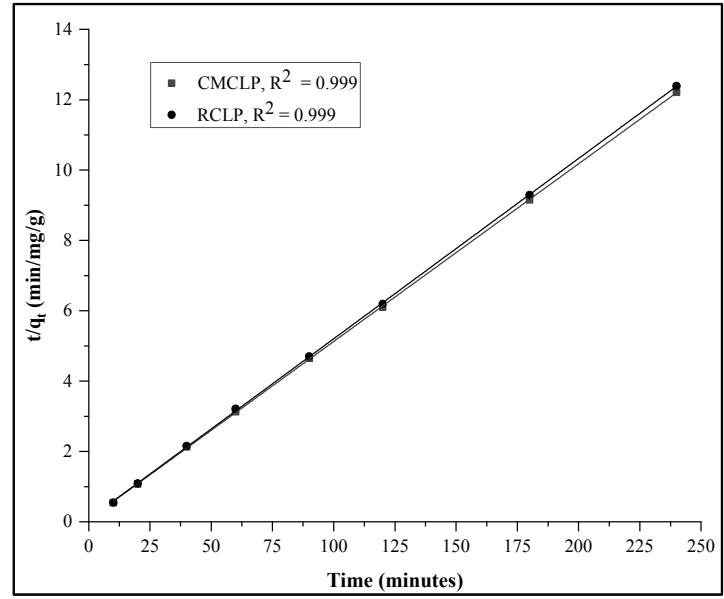

Figure 13: Pseudo second order kinetic model for adsorption of $C r$ (VI) onto RCLP and CMCLP

\section{Second Order Model}

The second order model can be expressed as

$$
\frac{\mathrm{dq}}{\mathrm{dt}}=\mathrm{K}_{2}^{\prime}\left(\mathrm{q}_{\mathrm{e}}-\mathrm{q}_{\mathrm{t}}\right)^{2}
$$

This equation can be further simplified as

$$
\frac{1}{q_{e}-q_{t}}=\frac{1}{q_{e}}+K_{2}^{\prime} t
$$

Where, $\mathrm{K}_{2}^{\prime}$ is the second order constant for adsorption $(\mathrm{g} / \mathrm{mg})$, ' $\mathrm{t}$ ' is the contact time and $\mathrm{q}_{\mathrm{e}}$ amounts of metal ion adsorbed at time ' $t$ ' and at equilibrium time respectively. The plot of $\frac{1}{q_{e}-q_{t}}$ and $\mathrm{q}_{\mathrm{t}}$ are versus ' $\mathrm{t}$ ' gives a straight line with slope equal to $\mathrm{K}_{2}^{\prime}$ and intercept $1 / \mathrm{q}_{\mathrm{e}}$ ' This linearity of these plots indicates the applicability of these model's capacities. ${ }^{20,29}$

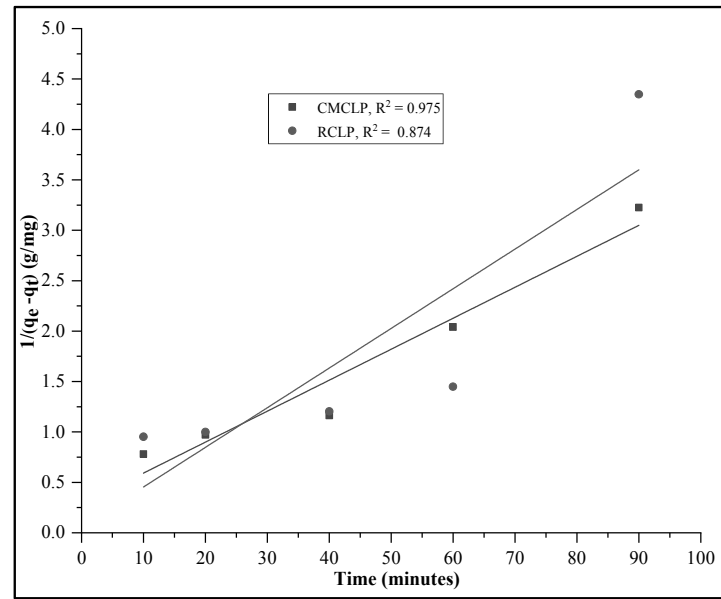

Figure 14: Second order kinetic model for adsorption of Cr(VI) onto RCLP and CMCLP Table 
Table 3: kinetic parameter for the bio sorption with correlation coefficient

\begin{tabular}{|c|c|c|c|c|c|c|c|c|c|c|}
\hline \multirow{2}{*}{$\begin{array}{l}\text { Adsorb- } \\
\text { ent }\end{array}$} & \multirow{2}{*}{$\begin{array}{l}\boldsymbol{q}_{\text {exp }} \\
(\boldsymbol{m g} \\
/ \\
\boldsymbol{g})\end{array}$} & \multicolumn{3}{|c|}{ Pseudo first order } & \multicolumn{3}{|c|}{ Pseudo second order } & \multicolumn{3}{|c|}{ Second order } \\
\hline & & $\begin{array}{c}K_{1} \\
\min ^{-1}\end{array}$ & $\begin{array}{l}\boldsymbol{q}_{\boldsymbol{e}} \\
(\boldsymbol{m g} \\
\quad / \\
g)\end{array}$ & $R^{2}$ & $\begin{array}{ll} & K_{2} \\
& (g / \\
\text { Min. } & \\
\text { Mg) } & \end{array}$ & $\begin{array}{l}q_{e} \\
m g / g\end{array}$ & $R^{2}$ & $\boldsymbol{K}_{2}^{\prime}$ & $\begin{array}{c}q_{e} \\
m g / g\end{array}$ & $R^{2}$ \\
\hline RCLP & 19.37 & $\begin{array}{l}1.8 \times \\
10^{-2}\end{array}$ & 1.49 & 0.93 & $\begin{array}{l}3.4 \times \\
10^{-2}\end{array}$ & 19.5 & 0.99 & $\begin{array}{l}3.9 \times \\
10^{-2}\end{array}$ & 16.64 & 0.87 \\
\hline CMCLP & 19.66 & $\begin{array}{l}1.7 \times \\
10^{-2}\end{array}$ & 1.54 & 0.99 & $\begin{array}{l}3.4 \times \\
10^{-2}\end{array}$ & 19.8 & 0.99 & $\begin{array}{l}3.0 \times \\
10^{-2}\end{array}$ & 3.50 & 0.97 \\
\hline
\end{tabular}

\section{Conclusions}

The optimum adsorption capacity of RCLP and CMCLP were achieved at initial $\mathrm{pH}$ (1), initial concentration $(20 \mathrm{mg} / \mathrm{L})$ of $\mathrm{Cr}(\mathrm{VI})$, equilibrium time (120 minutes)and dose $(150 \mathrm{mg})$. The maximum adsorption capacity of RCLP and CMCLP were found to be $186 \mathrm{mg} / \mathrm{L}$ and $228.1 \mathrm{mg} / \mathrm{L}$ respectively. The adsorption data tested both for Langmuir and Freundlich adsorption isotherm, most of the parameter indicates that it follows both Langmuir and Freundlich adsorption isotherm model but best fitting isotherm is Freundlich adsorption isotherm. Experimental data show that the best kinetic model is pseudo second order. Sample characters were analyzed by FT-IR, XRD and Boehm titration, from the FT-IR different functional group were identified, from XRD- amorphous nature of bioadsorbent was observed. And from Boehm titration more acidic functional group were detected in the surface of adsorbent.

\section{Acknowledgments}

The authors are very thankful to the head of department, Department of Chemistry,Tri-Chandra Multiple Campus Ghantaghar Kathmandu, Nepal for providing the available research facilities to conduct this research work, to Central Department of Chemistry for IR analysis and NAST for XRD analysis.

\section{References}

1. N. Gandhi, D. Sirish, S. Chardra, Adsorption studies of chromuim by using low cost adsorbents. Our Nature, 2013, 11(1), 11-16.

2. A. M. Frahan, N. M. Salem, A. H. Dujaili, A. Awwad,Bio sorption studies of Cr(VI) ions form electroplating waste water by walnut shell powder. American Journal of Environmental Engineering, 2012, 2(6), 188-195.

3. A. F. Ugbe, A. Pam, V. A. Ikudayisi, Thermodynamic properties of $\mathrm{Cr}(\mathrm{III})$ ions adsorption by sweet orange peel.American Journal of Analytical Chemistry, 2014, 5, 666-673.

4. D. Sivakumar, Hexavalent chromium removal in tannery waste water using rice husk silica. Global J. Environment Science,2015, 1(1), 27-40. 


\section{J. Nepal Chem. Soc., Vol. 36, 2017}

5. T. P. Dhungana, P. N. Yadav, Determination of chromium in tannery effluent and study of adsorption of $\mathrm{Cr}(\mathrm{VI})$ on saw dust and charcoal from sugar cane bagasse's. Jurnal of Nepal Chemical Society, 2009, 23, 93-103.

6. S. Chen, Q. Gao, Q. Li, X. Xu, K. Fu Adsorption of hexavalent Chromium from aqueous solution by modified corn stalk: a fixed bed column study. Bioresource Technology, 2012, 113, 114-120.

7. D. William, C. Birkinshaw, T. Francis, Heavy metal adsorbent prepared from the modification of cellulose: areview. Bio Resource Technology,2008, 99, 6709-6724.

8. T. N. Abdel-Ghani, A. G. EL-Chaghaby,Bio sorption for metal ions removal from aqueous solution: areview of Recent Studies. International Journal of Latest Research in Science and Technology,2014, 3(1), 24-42.

9. C. A. Poojari, D. S. Maind, A. S. Bhalerao, Effective removal of $\mathrm{Cr}(\mathrm{VI})$ from aqueous solution using rind of orange. Journal of Current Microbiology and Applied Science, 2015, 4(4), 653671.

10. R. P. Gautam, M. R. Pokhrel, Removal of $\mathrm{Cr}(\mathrm{VI})$ from aqueous solution using charred pomegranate waste. Journal of Nepal Chemical Society,2012, 29, 81- 88.

11. E. Vaiopoulou, P. Giras, Effects of chromium on activated sludge and on the performance of waste water treatment plants: a review.Water Research, 2012, 46, 549-570.

12. D. B. Khadka, P. Mishra, Adsorptive removal of $\mathrm{Cr}(\mathrm{VI})$ from aqueous solution by sugarcane biomass. Research Journal of Chemical Science, 2014, 4(5), 32- 40.

13. S. Regmi, K. N. Ghimire, M. R. Pokhrel, D. B. Khadka, Adsorptive removal and recovery of Aluminum(III), Iron(II) and Chromium(VI) on to a low cost functionalized phragmitieskark waste. Journal of Institute of Science and Technology, 2015, 20(2),145-152

14. D. Krishna, R. Padma Shree, Removal of chromium from aqueous solution by custard apple (Annona squamosa) peel powder as adsorbent. Internal Journal of Applied Science and Engineering, 2013, 11(2), 171-194.

15. C. Jeyaseelam, A. Gupta, Green tea leaves as a natural adsorbent for the removal of Cr(VI) from aqueous solution. Libertas Acadamica,2015, 9, 13-19.

16. M. Jain, V. K. Garg, K. Kardirvelu, Chromium removal from aqueous system and industrial waste water by agricultural wastes.Bioremediation Journal, 2013, 17(1), 30- 39.

17. B. Pangani, H. Poudyal, K. Inoue, H. Kawakita H., K. Ohto, H. Harada, K. B. Biswas, S. Alam, Optimization of an adsorption process for tetrafluoroborate removal by zirconium(VI) loaded orange waste gel from aqueous solution. Environmental Technology, 2011, 22(8), 845-850.

18. R. Hema Krishna, Comparative studies of isotherm and kinetics on the adsorption of $\mathrm{Cr}(\mathrm{VI})$ and $\mathrm{Ni}(\mathrm{II})$ from aqueous solution by powder of mosambi fruit pelings. Science Edomain International, 2014, 4(1), 26-45.

19. S. Mandina, F. Chigondo, M. Shumba, E. Sebata, Removal of Cr(VI) from aqueous solution using chemically modified orange (Citrus cinensis) peels. Journal of Applied Chemistry, 2013, 6(2), 66-75. 
20. A. KC, Study on sorption behavior of $\mathrm{Cr}(\mathrm{VI})$ onto acid treated banana peel powder from aqueous solution, A Dissertation Submitted to CentralDepartment of Chemistry, Tribhuvan University, 2016, 1-43.

21. M. H. Dehghani,S.Daryoush, I. Ali, A. Bhatnagar, Removal of $\mathrm{Cr}(\mathrm{VI})$ from aqueous solution using treated waste newspaper as low-cost adsorbent: kinetic modeling and isotherm studies. Journal of Molecular Liquids, 2016, 215, 671-679.

22. M. N. Hilal,A. A. Emam, A. A. El-bayaa, N. A. Badawy, A. E. Zidan, Adsorption of barium and iron ions from aqueous solution by the activated carbon produced from mazut ash. Life Science Journal, 2013, 10(4), 75-83.

23. D. S. Malik, C. K. Jain, A. K. Yadav, Removal of heavy metal from emerging cellulosic lowcost adsorbents: review. Research Gate Apl Water Science, 2016, 1-25.

24. S. R. Singh, A. P. Singh, Treatment of water containing $\mathrm{Cr}(\mathrm{VI})$ using the rice husk carbon as a new low-cost adsorbent. Internal Journal of Environment Research, 2012, 6(4), 917-924.

25. D. Balaarak, R. A. Yari, F. K. Mostafapour, Y. Mahdavi, A. A. Joghatoei, Agricultural waste as adsorbent for removal of Cr(VI) from aqueous solution.A Journal Arch Hyg Science, 2016, 5(4), 310-318.

26. S. H. Hasan, K. K. Singh, O. Prakash, M. Talaf, Y. S. HO, Removal of $\mathrm{Cr}(\mathrm{VI})$ from aqueous solution using agricultural waste maize bran. Journal of Hazardous Material, 2008, 152, 356365.

27. H. Sunil,K. V. Karthik, H. N. Pradeep, M. K. Shetty, Removal of $\mathrm{Cr}(\mathrm{VI})$ metal ions from waste water using alternative adsorbents: A comparative study.InternalJournal of Scientific and Research Publications, 2014, 4(1), 1-9.

28. B. D. Panta, Adsorptive removal of $\mathrm{Cr}(\mathrm{VI})$ from aqueous solution on to charred vetiver root, A Dissertation Submitted to Department of Chemistry, Tri-Chandra Multiple Campus, 2014, 1-47.

29. E. Mekonnan, M. Yitbarek, T. R. Soreta, Kinetic and thermodynamic studies of adsorption of $\mathrm{Cr}$ (VI) onto some selected local adsorbent. S. Afr. J. Chem, 2015, 68, 45-52. 